\title{
PENGARUH PENGETAHUAN KUALITAS BENIH, HARGA DAN LOKASI TERHADAP PEMILIHAN SUMBER BENIH PADI VARIETAS UNGGUL BARU DI KECAMATAN WARUNGKONDANG
}

\author{
Oleh: \\ M Yahya Ahmad **) \\ Silfiyyah Rahmah *)
}

\begin{abstract}
Abstrak
Indonesia merupakan negara dengan tingkat kebutuhan konsumsi akan pangan tinggi, pemilihan sumber benih yang baik sudah mengalami pengujian sertifikasi benih padi varietas unggul baru dari pemerintah dapat meningkatkan hasil produksi secara tinggi dan bisa memenuhi kebutuhan masyarakat Indonesia. Namun masih ada petani yang masih memilih sumber benih secara sendiri. Tujuan dari penelitian ini adalah untuk mengetahui berapa besar pengaruh pengetahuan kualitas benih, harga dan lokasi terhadap pemilihan sumber benih. Penelitian ini dilakukan pada bulan Maret sampai bulan Juni 2019 di Kecamatan Warungkondang. Untuk metode analisis ini menggunakan metode analisis regresi linier berganda dengan Statistical Package For Social Science (SPSS) Versi 25. Hasil penelitian ini menunjukkan bahwa pengaruh pengetahuan kualitas benih, harga dan akses lokasi mempunyai pengaruh secara signifikan terhadap pemilihan sumber benih padi varietas unggul baru. Semakin tinggi pengetahuan petani terhadap benih, semakin tinggi harga yang ditawarkan maka akan semakin mengerti dalam memilih sumber benih dan kualitas benih yang baik serta akses lokasi tidak menjadi masalah dalam pemilihan sumber benih karena sudah memiliki label sebagai tanda bahwa benih tersebut sudah mengalami beberapa pengujian sertifikasi benih berlabel.
\end{abstract}

Kata Kunci : Pengetahuan Kualitas Benih, Harga, Akses Lokasi, Pemilihan Sumber Benih.

\begin{abstract}
Indonesia is a country with a high level of consumption need for food, the selection of good seed sources has undergone certification testing of new superior varieties of rice seeds from the government can increase production yields high and can meet the needs of the people of Indonesia. But there are still farmers who still choose their own seed sources. The purpose of this study was to determine how much influence the knowledge of seed quality, price and location on the selection of seed sources. This research was conducted in March to June 2019 in Warungkondang District. For this analysis method using multiple linear regression analysis method with Statistical Package For Social Science (SPSS) Version 25. The results of this study indicate that the influence of knowledge of seed quality, price and location access bas a significant influence on the selection of new superior rice seed source sources. The higher the farmer's knowledge of seeds, the higher the price offered will better understand the choice of seed sources and good quality seeds and access to location is not a problem in selecting seed sources because it already has a label as a sign that the seed has undergone several seed certification testing labeled.
\end{abstract}

Keywords: Seed Quality Knowledge, Price, Access Location, Selection of Seed Sources.

*) Alumni Fakultas Sains Terapan UNSUR

**) Dosen Fakultas Sains Terapan UNSUR 


\section{PEDAHULUAN}

Di zaman globalisasi serta kemajuan teknologi sangat mempengaruhi pola pikir atau persepsi masyarakat tentang berbagai macam hal termasuk produk mengingat teknologi masa kini yang bisa membantu dalam meningkatkan kualitas produk suatu perusahaan. Berdasarkan info dari kementerian pertanian data yang diperoleh dari BPS bahwa tingginya konsumsi beras masyarakat Indonesia rata-rata sebesar 114,9/kg/kapita/tahun (BPS, 2017). Oleh karena itu diharapkan pemilihan benih padi yang baik dapat meningkatkan hasil panen yang tinggi, agar bisa memenuhi kebutuhan masyarakat yang semakin lama semakin meningkat, pengetahuan akan kualitas benih sangat diperlukan oleh para petani dan tidak hanya berdasarkan kualitas benih saja pemilihan tempat yang strategis juga merupakan salah satu strategis untuk menarik minat petani dalam memilih sumber benih yang baik, semakin dekat akses tempat dengan para pelanggan dan lahan yang sesuai dengan kebutuhan benih varietas unggul baru maka akan sangat mengutungkan bagi pihak konsumen dalam memenuhi keinginannya.

Selain hal tersebut harga juga bisa mempengaruhi pemilihan sumber benih karena ketika melihat dari segi harga, petani akan memperhitungkan segala kebutuhan untuk lahan yang akan dikelolanya, maka dari itu pemilihan harga pada benih juga menjadi salah satu hal yang akan petani pertimbangkan.

Harga sumber benih yang baik seiring waktu bisa berbeda hal ini sering disebabkan keuangan petani yang tidak bisa membeli benih. Biasanya petani mengembangkan benih dari tanam sebelumnya, hal ini sangat mempengaruhi hasil padi yang diperoleh akan menurun.

Pemilihan sumber benih menjadi hal yang akan mempengaruhi hasil panen, dimana nantinya akan diterima oleh para konsumen (petani) dan pemilihan sumber benih yang baik yaitu benih yang telah memenuhi persyaratan sertifikasi (pelabelan). Menurut Irawati (2009) Warsono (2013) Benih padi bersertifikat adalah benih yang sudah mengalami beberapa proses mulai dari penyiapan lahan, pengolahan, penanaman, pemeliharaan dan panen sampai pasca panen serta penyimpanan benih dengan baik, maka diperoleh benih yang memiliki mutu yang baik yaitu benih varietas unggul baru IR 32 dengan tingkat ketahanan terhadap hama sangat baik, pulen serta harum dengan jangka waktu panen $\leq$ 3-4 bulan serta sudah bersertifikat maka akan meningkatkan produktivitas tanaman padi yang tinggi antara 8-9 ton dan sudah dikembangkan dari bulan Agustus 2018 sampai dengan sekarang. Dampak ekonomisnya bisa meningkatkan efisiensi dan pendapatan petani melalui peningkatan produktivitas (LL Mustain 2005 ; Podesta 2009). Mengingat kualitas produk benih yang baik dapat mempengaruhi hasil panen nanti. Lokasi dan harga menjadi salah satu pertimbangan petani dalam memilih benih yang baik atau tidak. Maka dari itu diharapkan petani bisa memilih sumber benih padi yang baik yang sudah bersertifikat dari instansi terkait, namun masih ada beberapa petani yang tidak mengetahui informasi tentang pentingnya benih yang sudah bersertifikat (berlabel) karena segi harga yang tidak memungkinkan untuk membeli benih biasanya petani mengambil langkah dengan mengembangkan benih hasil dari tanam sebelumnya.

Berdasarkan hasil diatas maka dilakukan penelitian dengan tujuan untuk mengkaji: 1) Untuk mengetahui besarnya pengetahuan petani tentang kualitas benih padi varietas unggul baru, 2) untuk mengetahui besarnya pengaruh pengetahuan kualitas benih varietas unggul baru terhadap pemilihan sumber benih padi varietas unggul baru, 3) untuk mengetahui besarnya pengaruh harga terhadap pemilihan sumber benih padi varietas unggul baru, 4) untuk mengetahui besarnya pengaruh lokasi terhadap 
pemilihan sumber benih padi varietas unggul baru, 5) untuk mengetahui besarnya pengaruh pengetahuan kualitas benih, harga dan lokasi terhadap pemilihan sumber benih padi varietas unggul baru.

Dengan dilakukannya pengujian ini diharapkan pengaruh pengetahuan kualitas akan menjadi masukan bagi pengambil kebijakan yang menyediakan benih unggul agar dapat diakses oleh petani.

\section{METODE PENELITIAN}

Penelitian ini dilakukan di kecamatan Warungkondang di beberapa desa yang menanam benih padi varietas unggul baru. Penelitian ini dilaksanakan selama 4 bulan dari bulan Maret 2019 Juni 2019. Populasi untuk penelitian adalah para petani beras varietas unggul baru di kecamatan Warungkondang sedangkan metode pengambilan sampelnya menggunakan metode Slovin (Umar, 2005). Berdasarkan rumus tersebut sampel minimum dari populasi sebanyak 97 dan untuk memudahkan dalam penelitian maka jumlah populasi yang diambil dalam penelitian ini berjumlah 100 respoden.

Pada penelitian ini variabel yang dikaji yaitu: pengetahuan kulitas benih, harga dan lokasi. Untuk Indikator variabel pengetahuan kualitas benih adalah kemurnian benih, hasil panen bagus (produktivitas tinggi), viabilitas tinggi, kesesuaian dengan tempat budidaya, benih berlabel dan tahan terhadap serangan hama. Indikator harga adalah harga produk terjangkau, kesesuaian harga dengan kualitas dan harga yang sesuai dengan manfaat. Indikator lokasi adalah lokasi mudah untuk dijangkau, tempat dekat dengan konsumen dan jarak kesesuaian dengan tempat budidaya, benih berlabel dan tahan terhadap serangan hama. Indikator harga adalah harga produk terjangkau, kesesuaian harga dengan kualitas dan harga yang sesuai dengan manfaat. Indikator lokasi adalah lokasi mudah untuk dijangkau, tempat dekat dengan konsumen dan jarak dari rumah dekat terhadap sumber benih. Indikator pemilihan sumber benih adalah formal dan informal. Untuk skala pngukuran menggunakn skala likert yaitu sangat setuju, setuju, netral, tidak setuju, dan sangat tidak setuju.

Adapun metode analisis dalam penelitian ini adalah metode analisis deskriptif kuantitatif. Yaitu analisis yang berkaitan dengan angka, frekuensi serta presentase. Dengan cara pengujian uji validitas dengan menggunakan loading faktor, reliabilitas atau nyata, analisis regresi linier berganda untuk megetahui besarnya pengaruh variabel bebas kepada variabel terikat, dan yang terakhir uji $\mathrm{T}$. 
Tabel 1. Variabel Penelitian.

\begin{tabular}{|c|c|c|c|}
\hline Varibel & Konsep Variabel & Indikator & Skala \\
\hline $\begin{array}{l}\text { Pengetahu } \\
\text { an Kualitas } \\
\text { Benih }\left(\mathrm{X}_{1}\right)\end{array}$ & $\begin{array}{l}\text { Menurut Suena (2009) kualitas } \\
\text { benih yang baik merupakan } \\
\text { kemampuan perkecambahan yang } \\
\text { tinggi, tahan terhadap serangan } \\
\text { penyakit dan sudah mengalami } \\
\text { bebagai tahap pengujian benih yang } \\
\text { sesuai dengan persyaratan benih } \\
\text { berlabel. }\end{array}$ & $\begin{array}{l}\text { 1. Kemurnian benih } \\
\text { 2. Hasil panen bagus (produktivitas } \\
\text { tinggi) } \\
\text { 3. Viabilitas tinggi } \\
\text { 4. Kesesuaian dengan tempat } \\
\text { budidaya } \\
\text { 5. Benih berlabel } \\
\text { 6. Tahan terhadap serangan hama. }\end{array}$ & Ordinal \\
\hline Harga (X2) & $\begin{array}{l}\text { Menurut Tjiptono, } 2006 \text { harga } \\
\text { merupakan sebuah uang (uang } \\
\text { moneter) / aspek lain (non } \\
\text { moneter) yang memiiki kegunaan } \\
\text { tertentu untuk mendapatkan } \\
\text { manfaat dari barang maupun jasa. }\end{array}$ & $\begin{array}{l}\text { 1. Harga produk terjangkau } \\
\text { 2. kesesuaian harga dengan } \\
\text { kualitas } \\
\text { 3. harga yang sesuai dengan } \\
\text { manfaat. }\end{array}$ & Ordinal \\
\hline $\begin{array}{l}\text { Lokasi } \\
\text { (X3) }\end{array}$ & $\begin{array}{l}\text { Menurut Kotler dan Keller (2009) } \\
\text { lokasi sebagai sarana aktivitas yang } \\
\text { diperuntukan untuk konsumen } \\
\text { dalam memperoleh barangnya. }\end{array}$ & $\begin{array}{l}\text { 1. Lokasi mudah untuk dijangkau } \\
\text { 2. Tempat dekat dengan konsumen } \\
\text { 3. Jarak dari rumah dekat terhadap } \\
\text { sumber benih }\end{array}$ & Ordinal \\
\hline $\begin{array}{l}\text { Pemilihan } \\
\text { Sumber } \\
\text { benih (Y) }\end{array}$ & $\begin{array}{l}\text { Menurut Leksono, } 2004 \\
\text { mengemukakan bahwa sumber } \\
\text { benih merupakan sarana atau } \\
\text { tempat dimana semua benih } \\
\text { diproses dan dilakukan } \\
\text { pengelolaannya. }\end{array}$ & $\begin{array}{l}\text { 1. Fomal } \\
\text { 2. Informal }\end{array}$ & Ordinal \\
\hline
\end{tabular}

\section{HASIL DAN PEMBAHASAN}

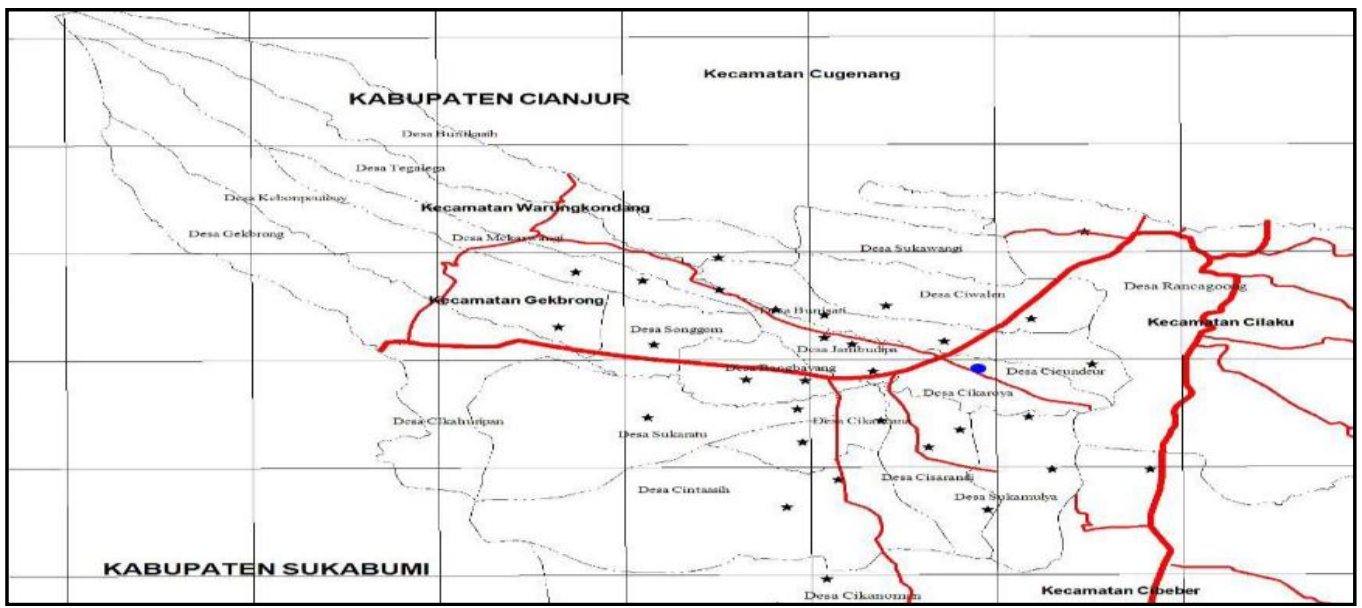

Kecamatan

Warungkondang memiliki 11 Desa. Dari 11 Desa tersebut peneliti memfokuskan hanya 4 Desa saja yaitu Desa Sukamulya, Desa Ciwalen, Desa Tegalega dan Desa Sukawangi.

Kecamatan Warungkondang juga menjadi bahan untuk berbagai pengujian benih mengingat lahan serta kondisi yang sesuai untuk memulai pegembangan benih baru dari pemerintah untuk benih yang dikembangkan yaitu benih IR 30,32,34 dan sebagainya. Untuk 4 Desa tersebut sebagian besar Desa menanam benih varietas unggul baru jenis IR 32 yang memiliki rasa pulen, harum serta memiliki ketahanan terhadap hama sangat baik hampir sama dengan jenis padi lokal pandanwangi yang membedakan hanya 
jangka waktu padi IR 32 sekitar 3-4 bulan baru panen, untuk rata-rata pendidikan terkahir petani di ke 4 Desa ini sama seperti Desa yang lain yaitu hanya sampai $\mathrm{Sd}$ sederajat, sebagian besar yang mengelola lahan adalah laki-laki, memiliki usia diatas 30 tahun lebih artinya sudah banyak pengalaman tentang bertani serta biasanya mengikuti jejak orangtua terdahulu dan lebih banyak hanya menjadi buruh tani atau penggarap sebagian lagi sebagai pemilik lahan.

\section{Analisis faktor}

Adapun hasil output analisis faktor yang dilakukan pada pengetahuan kualiats benih (X1) adalah sebagai berikut:

Tabel 2. Hasil Uji Validitas KMO and Bartlett's Test Variabel Pengetahuan Benih.

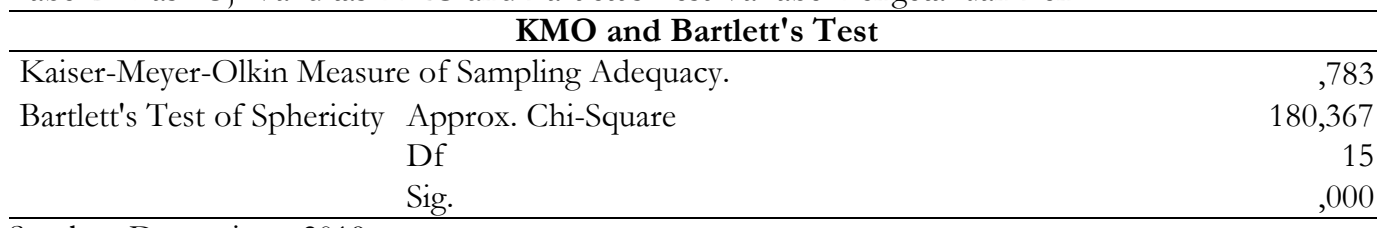

Sumber: Data primer 2019

Berdasarkan Tabel 2. diatas terlihat hasil ouput analisis faktor terhadap variabel pengetahuan kualitas benih $\left(\mathrm{X}_{1}\right)$ diperoleh nilai Kaiser Meyer-
Olkin Measure of Sampling Adequacy (KMO MSA) sebesar $0.783>0.5$, yang berarti dapat dinyatakan valid.

Tabel 3. Hasil output uji validitas dengan analisis faktor terhadap variabel pengetahuan kualitas benih

\begin{tabular}{|c|c|c|}
\hline Item & Loading faktor & Keterangan \\
\hline $\mathrm{X} 1.1$ & ,834 & Valid \\
\hline $\mathrm{X} 1.2$ & ,746 & Valid \\
\hline $\mathrm{X} 1.3$ & ,700 & tidak valid \\
\hline $\mathrm{X} 1.4$ & 638 & tidak valid \\
\hline $\mathrm{X} 1.5$ & ,777 & Valid \\
\hline $\mathrm{X} 1.6$ & 607 & tidak valid \\
\hline
\end{tabular}

Sumber: Data primer 2019.

Berdasarkan Tabel 3. di atas hasil ouput uji validitas dengan analisis faktor terhadap variabel pengetahuan kualitas benih (X1) diperoleh loading faktor dengan item X1.1 sebesar 0,834, X1.2 sebesar $0,746, \mathrm{X} 1.3$ sebesar 0,662, X1.4 sebesar 0,638, X1.5 sebesar 0,777, X1.6 sebesar 0.607 dan masing-masing indikator pada tabel itemX1.1, X1.2, X1.5 menunjukkan loading faktor $>0,7$ maka ketiga indikator variabel pengetahuan kualitas benih (X1) dinyatakan valid dapat dianalisis lebih lanjut dan untuk item X1.3, X1.4, X1.6 menunjukkan loading faktor $<0,7$ maka untuk ketiga indikator variabel ini tidak valid di reduksi dan tidak dianalisis lebih lanjut.

Tabel 4. Hasil ouput analisis faktor terhadap variabel Harga (X2).

\begin{tabular}{|c|c|c|}
\hline \multicolumn{3}{|c|}{ KMO and Bartlett's Test } \\
\hline Kaiser-Meyer-Olkin Measu & of Sampling Adequacy. & ,701 \\
\hline Bartlett's Test of Sphericity & $\begin{array}{l}\text { Approx. Chi-Square } \\
\text { df } \\
\text { Sig. }\end{array}$ & $\begin{array}{c}63,855 \\
6 \\
, 000\end{array}$ \\
\hline
\end{tabular}

Sumber: Data primer 2019.

Berdasarkan Tabel 4 di atas terlihat hasil ouput analisis faktor terhadap variabel Harga (X2) diperoleh nilai Kaiser
Meyer-Olkin Measure of Sampling Adequacy (KMO MSA) sebesar $0.701>0.5$, yang berarti dapat dinyatakan valid. 
Tabel 5. Hasil ouput uji validitas dengan analisis faktor terhadap variabel Harga (X2).

\begin{tabular}{|c|c|c|}
\hline Item & Loading faktor & Keterangan \\
\hline $\mathrm{X} 2.1$ & ,831 & Valid \\
\hline $\mathrm{X} 2.2$ & ,677 & tidak valid \\
\hline $\mathrm{X} 2.3$ & ,710 & Valid \\
\hline $\mathrm{X} 2.4$ & ,641 & tidak valid \\
\hline
\end{tabular}

Sumber: Data primer 2019.

Berdasarkan Tabel 5. di atas hasil ouput uji validitas dengan analisis faktor terhadap variabel Harga (X2) diperoleh loading faktor dengan item X2.1 sebesar 0,831, X2.2 sebesar 0,677, X2.3 sebesar 0,710, X2.4 sebesar 0,641 dan masingmasing indikator pada tabel item X2.1, X2.3 menunjukkan loading faktor $>0,7$ maka kedua indikator variabel harga (X2) dinyatakan valid dapat dianalisis lebih lanjut dan untuk item X2.2, X2.4 menunjukkan loading faktor $<0,7$ maka untuk kedua indikator variabel ini tidak valid di reduksi dan tidak dianalisis lebih lanjut.

Tabel 6. Hasil ouput analisis faktor terhadap variabel Lokasi (X3).

\begin{tabular}{|c|c|c|}
\hline \multicolumn{3}{|c|}{ KMO and Bartlett's Test } \\
\hline \multicolumn{2}{|c|}{ Kaiser-Meyer-Olkin Measure of Sampling Adequacy. } & ,593 \\
\hline Bartlett's Test of & Approx. Chi-Square & 18,535 \\
\hline Sphericity & $\mathrm{df}$ & 3 \\
\hline & Sig. &, 000 \\
\hline
\end{tabular}

Sumber: Data primer 2019.

Berdasarkan Tabel 6. Di atas terlihat hasil ouput analisis faktor terhadap variabel Lokasi (X3) diperoleh nilai Kaiser Meyer-Olkin Measure of Sampling Adequacy (KMO MSA) sebesar $0.593>$ 0.5 , yang berarti dapat dinyatakan valid

Tabel 7. Hasil ouput uji validitas dengan analisis faktor terhadap variabel Lokasi (X3).

\begin{tabular}{lrc}
\hline Item & Loading faktor & Keterangan \\
\hline X3.1 &, 767 & Valid \\
X3.2 &, 647 & tidak valid \\
X3.3 &, 712 & Valid \\
\hline
\end{tabular}

Sumber: Data primer 2019.

Berdasarkan Tabel 7. di atas hasil ouput uji validitas dengan analisis faktor terhadap variabel Lokasi (X3) diperoleh loading faktor dengan item X3.1 sebesar 0,767, X3.2 sebesar 0,647, X3.3 sebesar 0,712641 dan masing-masing indikator pada tabel item X3.1, X3.3 menunjukkan

Tabel 8. Hasil ouput analisis faktor terhadap variabel Sumber Benih (Y).

\section{KMO and Bartlett's Test}

Kaiser-Meyer-Olkin Measure of Sampling Adequacy.

Bartlett's Test of Approx. Chi-Square

Sphericity

df

Sig. , 000

Sumber: Data primer 2019.

Berdasarkan Tabel 8. di atas terlihat hasil ouput analisis faktor terhadap variabel Sumber Benih (Y) diperoleh nilai
Kaiser Meyer-Olkin Measure of Sampling Adequacy (KMO MSA) sebesar $0.657>$ 0.5 , yang berarti dapat dinyatakan valid. 
Tabel 9. Variabel Sumber benih (Y).

\begin{tabular}{|c|c|c|}
\hline Item & Loading faktor & Keterangan \\
\hline Y1 &, 767 & Valid \\
\hline $\mathrm{Y} 2$ & 888 & Valid \\
\hline Y3 &,- 844 & tidak valid \\
\hline
\end{tabular}

Sumber: Data primer 2019.

Variabel Sumber benih (Y) diperoleh loading faktor dengan item Y1 sebesar 0,765 , X3.2 sebesar 0,888, masingmasing indikator pada tabel component Matrix kolom 1 menunjukkan loading faktor $>0,7$ kecuali indikator Y3 sebesar $0,844<0,7$ sehingga dapat disimpulkan bahwa hanya dua indikator variabel Sumber Benih $(Y)$ dinyatakan valid dapat dianalisis lebih lanjut, sementara indikator Y3 di reduksi dan tidak dianalisis lebih lanjut.

\section{Uji Reliabilitas Pengetahuan Kualitas Benih (X1)}

Maka dapat disimpulkan bahwa nilai Pada kuesioner variabel X1 menunjukkan bahwa nilai Cronbach's Alpha nya sebesar 0,805 pada tiap-tiap pernyataan. Cronbach's Alpha $\geq 0,6$ dari item pernyataan sebanyak 6 point, oleh karena itu data ini reliable atau terpercaya, sebagimana dapat kita lihat pada tabel dibawah

Tabel 10. Hasil Pengujian Realibilitas X1, X2, X3, Y.

\begin{tabular}{|c|c|c|c|}
\hline Variabel & Cronbach's Alpha & $\mathbf{N}$ of items & Keterengan \\
\hline $\mathrm{X} 1$ & 805 & 6 & Reliable \\
\hline $\mathrm{X} 2$ & 680 & 4 & Reliable \\
\hline X3 & ,493 & 3 & Tidak reliable \\
\hline Y & 675 & 2 & Reliable \\
\hline
\end{tabular}

Sumber: Data primer 2019

Metode analisis regresi linier ini digunakan untuk mengukur berapa besar pengaruh variabel independen (X)

Tabel 11. Analisis Regresi Linier Berganda.

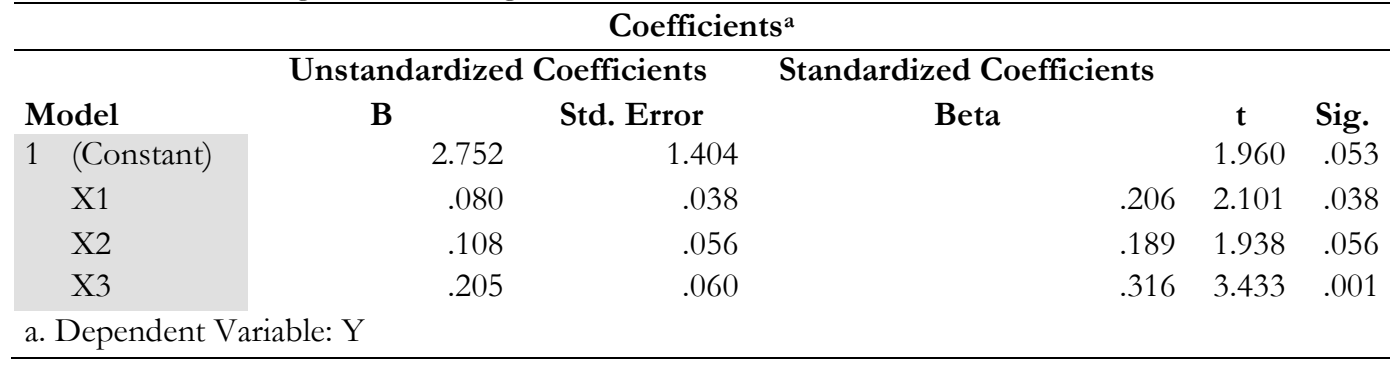

Berdasarkan hasil dari olahan

SPSS 25 maka diperoleh hasil persamaan regresi sebagai berikut:

$$
\begin{array}{r}
Y=2.752+0,80 X_{1}+0,108 X_{2} \\
+0,205 X_{3}+e
\end{array}
$$

Keterangan

$$
\begin{array}{ll}
Y & =\text { Sumber benih } \\
X_{1} & =\text { Pengetahuan kualitas benih } \\
X_{2} & =\text { Harga } \\
X_{3} & =\text { Akses lokasi }
\end{array}
$$

terhadap variabel dependen (Y) baik secara parsial maupun secara simultan.

X)

Coefficients $^{a}$ 


\section{Uji T}

Adapun Uji parsial dilakukan untuk mengetahui pengaruh variabel bebas terhadap variabel terikat secara sendirisendiri, dari hasil data yang diperoleh pada tabel 4.33 maka hasil analisisnya yaitu sebagai berikut:

$\mathrm{T}$ tabel $=\mathrm{t}(\mathrm{a} / 2 ; \mathrm{n}-\mathrm{k}-1)=(0,10 / 2 ;$ $100-3-1=96)=1,660$.

\section{Uji F}

\section{Menurut Sudrajat} mengemukakan bahwa uji $\mathrm{F}$ digunakan untuk mengetahui apakah model regresi yang dianalisis memiliki tingkat kelayakan yang tinggi yaitu variabel-variabel yang digunakan model regresi untuk menjelaskan kenyataan yang dianalisis dengan kriteria pengujian sebagai berikut:

1.Jika nilai probabilitas $<$ dari 0,05 maka model tersebut dinyatakan layak.

2. Jika nilai probabilitas $>$ dari 0,05 maka model tersebut dinyatakan tidak layak

Maka dari itu untuk mengetahui tingkat kelayakan dari ketiga model variabel bebas (X1, X2, X3) terhadap variabel Y. berdasarkan tabel 4.34 maka diperoleh analisis analisis data sebagai berikut:

Tabel 12. Uji Kelayakan Model Dengan Uji F.

\begin{tabular}{|c|c|c|c|c|c|c|}
\hline \multicolumn{7}{|c|}{ ANOVA $^{a}$} \\
\hline \multicolumn{2}{|c|}{ Model } & Sum of Squares & df & Mean Square & $F$ & Sig. \\
\hline 1 & Regression & 13.824 & 3 & 4.608 & 7.825 & $.000^{\mathrm{b}}$ \\
\hline & Residual & 56.536 & 96 & .589 & & \\
\hline & Total & 70.360 & 99 & & & \\
\hline
\end{tabular}

Sumber: Data primer 2019.

F tabel: $\mathrm{F}(\mathrm{k} ; \mathrm{n}-\mathrm{k})=(3 ; 100-2=98)=2,70$.

Hasil perhitungan statistic menunjukkan bahwa nilai $\mathrm{F}$ hitung $>\mathrm{F}$ tabel yaitu 7,825 dengan nilai signifikasinya sebesar $0,000<$ dari 0,005 . Maka dari itu dapat disimpulkan bahwa seluruh variabel pengetahuan kualias benih X1, Harga X2 dan Lokasi X3 memiliki pengaruh yang sangat besar secara simultan atau bersama-sama terhadap sumber benih Y.

\section{KESIMPULAN}

Berdasarkan penelitian yang telah dilakukan mengenai pengaruh pengetahuan kualitas benih, harga dan lokasi terhadap pemilihan sumber benih. maka dapat disimpulkan sebagai berikut :

1. Tingkat pengetahuan petani akan benih sengat tinggi melihat dari jawaban petani yang sangat paham dengan apa yang ditanyakan.

2. Variabel pengetahuan kualitas benih berpengaruh secara positif dan signifikan terhadap pemilihan sumber benih. Karena semakin petani berpengetahuan tentang kualitas benih terhadap pernyataan yang sudah diajukan maka petani tidak akan salah dalam memilih sumber benih yang jelas.

3. Variabel harga berpengaruh secara positif dengan nilai signifikasinya dapat diterima untuk kepentingan strategis terhadap pemilihan sumber benih. Karena petani sudah mengetahui bahwa semakin mahal harga benih maka akan semakin berkualitas.

4. Variabel lokasi berpengaruh secara positif dan signifikan terhadap pemilihan sumber benih. Meskipun jauh tidak menjadi persoalan karena ada faktor lain yang mempengaruhi petani dalam memlih benih yang jelas.

5. Variabel pengetahuan kualitas benih, harga dan lokasi secara simultan atau bersama-sama mempunyai pengaruh yang signifikan terhadap pemilihan sumber benih, karena ketika sudah 
mengetahui pengetahuan kualitas benih, harga dan lokasi pun tidak menjadi masalah untuk memilih sumber benih yang baik dan sudah mempunyai label serta bisa meningkatkan hasil produksi panen.

\section{DAFTAR PUSTAKA}

Badan Pusat Statistik. 2017. Badan Pusat Statistike Tabel Dinamis. Diambil kembali dari badan pusat statistic https://www.bps.go.id/site/resulT $\underline{\mathrm{ab}}$ diakses pada tanggal april pukul 10.00 wib.

Irawati N. 2009. Analisis Sikap dan Kepuasan Petani Padi Terhadap Benih Padi (Oriza Sativa) Varietas Unggul di Kota Solok Sumatera Barat [Skripsi]. Bogor: Fakultas Ekonomi dan Manajemen, Institut Pertanian Bogor.

Kotler, Philip dan Kevin Lane Keller. 2009. Manajemen Pemasaran. Edisi 13 Jilid satu. Erlangga: Jakarta.

Leksono, B. 2004. Litbang Pemuliaan Acacia dan Eucalyptus untuk penyediaan benih unggul dan perangan dalam mendukung program GN-RHL. Prosiding Ekspose hasil-hasil penelitian P3BPTH, 24 Desember 200. Jogjakarta.

Mustain, LL (2005) Strategi pengembangan beib padi bersertifikat pada dinas pertanian dan peternakan kabupaten lombok timur NTB. Masters thesis, Institut Pertanian Bogor.

Podesta. 2009. Pengaruh penggunaan benih bersertifikat terhadap efisiensi dan pendapatan usahatani padi pandanwangi (skripsi). Bogor.
Fakultas Ekonomi dan Manajemen, Institut Pertanian Bogor.

Sadjad, S. 1993. Dari Benih Kepada Benih. Jakarta: PT. Gramedia. Siregar, H. 1981. Budidaya Tanaman Padi di Indonesia. Sastra Hudaya. Bogor. 318 hal. Dalam Ishaq I. 2009. Petunjuk Khusus: Penangkaran Benih Padi. Lembang (ID): Balai Pengkajian Teknologi Petanian (BPTP) Jawa Barat Departemen Pertanian.

Saheda, Amatu As. 2008. Preferensi dan Kepusan Petani Terbadap Benib Padi Varietas Lokal Pandawangi di Kabupaten Cianjur, Skripsi Fakultas Pertanian, Institut Pertanian Bogor.

Sembiring, H. 2010. Ketersediaan Inovasi Teknologi Unggulan dalam Meningkatkan Produksi Padi Menunjang Swasembada dan Ekspor. Dalam Prosiding Nasional Hasil Penelitian Padi 2009. Inovasi Teknologi Padi untuk Mempertahankan Swasembada dan Mendorong Ekspor Beras. Balai Besar Padi. Badan Litbang Pertanian. Kementrian Pertanian Jakarta.

Tjiptono, Fandy. 2006. Manajemen Jasa, Edisi pertama, Yogyakarta: Andi

Umar, Husein. 2005. Metode Penelitian untuk Tesis dan Bisnis, Jakarta: Grafindo Persada.

Warsono. 2013. Kegiatan sertifikasi benih padi (Oryza Sativa) di Balai Pengawasan Sertifikasi Benih (BPSB) Provinsi Jawa Tengah [tugas akhir]. Bogor (ID): Institut Pertanian Bogor. 